\title{
Donald G. Barceloux: Medical Toxicology of Drug Abuse. Synthesised Chemicals and Psychoactive Plants
}

\author{
Neil C. Henney
}

(C) Springer-Verlag Berlin Heidelberg 2014

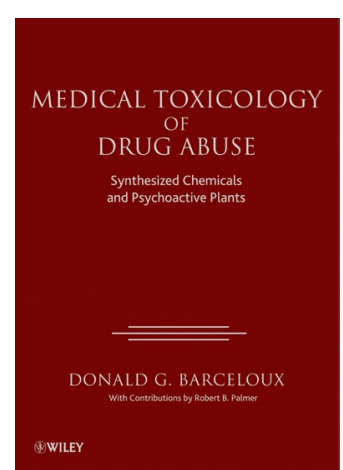

\section{Bibliography}

Medical Toxicology of Drug Abuse:

Synthesised Chemicals and

Psychoactive Plants

Donald G. Barceloux

John Wiley \& Sons, Hoboken,

NJ, USA, 2012, pp 1064

ISBN 978-0-471-72760-6

GPB 130.00, EUR 156.00

The second in a series of four volumes on medical toxicology, this book is immediately a welcome resource for medics, pharmacists, and toxicologists and will surely be a valued addition to any department of emergency medicine or poisons centre. This volume focuses on those compounds that are used (or abused?) for pleasure or non-medical gain, but in doing so may cause harm; from the ancient and historic use of peyote by the native North Americans, to growth hormone and blood doping, through to designer club drugs like mephedrone.

The book is extremely well structured throughout-each section on a drug or group of drugs follows the same format providing invaluable information on the chemistry, pharmacology, clinical response, screening, treatment, and so on, in detail that leaves other reference books wanting. The author has drawn from a large number of reference sources to compile each section, and diagrams, photographs and chemical structures are provided to further supplement the text. The content pages are laid out well, and the index pages comprehensive enough to easily and quickly locate pages of interest by compound or clinical presenting features.

Rather than simply focussing on only the "usual" compounds that may be misused, this text also provides detailed information, and a chemical and clinical perspective, on drugs and substances that are rarely touched upon elsewhere in this context, such as the industrial hydrocarbons. Gasoline sniffing is not a topic I would expect to find in many other resource books, but is a particular problem in some communities across the world and warrants inclusion in a comprehensive resource such as this. Coverage of topics such as blood doping and nutritional supplements, which may affect an individual's chances in sporting competitions, is included and given the reported use of such methods by athletes to enhance their performance this is a further welcome addition. The value of the book for this reason (the comprehensive coverage) are immeasurable.

This is an excellent book, and I thoroughly recommend it to those listed in my opening remarks. 